\title{
Angiographic correlates of blood loss in endoscopic excision of juvenile nasopharyngeal angio-fibroma
}

\author{
Subhash Kumar ${ }^{1 *}$ and Kranti Bhavana ${ }^{2}$ \\ ${ }^{1}$ Department of Radiodiagnosis, All India Institute of Medical Science Patna, Phulwarisharif, Patna, Bihar, India \\ ${ }^{2}$ Department of ENT, All India Institute of Medical Science Patna, Phulwarisharif, Patna, Bihar, India
}

\begin{abstract}
Objective: To evaluate the angiographic findings with relation to intraoperative blood loss in a series of juvenile nasopharyngeal angiofibroma (JNA) operated endoscopically.

Methods: Retrospective chart review of clinical, angiographic and operative details was done of all consecutive patients of Radkowski grade IIC or IIIA JNA who had undergone superselective polyvinyl alcohol (PVA) particle embolisation of external carotid artery (ECA) feeders in single session followed by endoscopic excision during the period of August 2014 to March 2019.

Results: 22 cases $(14.7 \pm 2.7$ years, range $10-24$ years $)$ with mean tumour size $6.7 \mathrm{~cm}(5.8-12.5 \mathrm{~cm}$ range $)$ were identified. 15/22 cases had bilateral ECA territory blood supply and 7/22 had additional supply from internal carotid artery (ICA) branches. Mean tumour devascularisation was $60 \%$ (50-100\% range) and intraoperative blood loss was $362 \mathrm{ml} \pm 176.2 \mathrm{ml}$ (range $50 \mathrm{ml}-1500 \mathrm{ml}$ ). Isolated unilateral or bilateral internal maxillary artery (IMA) and/or ascending pharyngeal artery $(\mathrm{AscPhA})$ supply had least blood loss (average $150 \mathrm{ml}$ ), and patients with additional ICA supply had disproportionate increase in blood loss (700 ml in unilateral and $1350 \mathrm{ml}$ in bilateral ICA supply). No neurological complications were seen. Complete endoscopic tumour removal was obtained in 19 cases. 2 cases underwent repeat surgery with complete excision, and one kept on follow up. Two patient received autologous blood transfusion.
\end{abstract}

Conclusions: Unilateral or bilateral IMA and AScPhA artery supply is associated with high embolization rates and low blood loss. ICA supply contributes to lower embolization rates and increased blood loss.

\section{Introduction}

Juvenile nasopharyngeal angiofibroma (JNA) is a rare, benign, locally aggressive, hyper vascular tumour of adolescent males with tendency of spontaneous regression after puberty, and accounting for 0.05 to $0.5 \%$ of all head and neck neoplasms [1-4].

JNA management has been evolving [5], and over time, several staging systems have been proposed for JNA, including those of Sessions [6], Fisch [7], Chandler [8], Andrews [9], Radkowski [10] and Onerci [11].

Surgical management of JNA has been traditionally challenging, due to the multidirectional local spread and excessive haemorrhagic tendency, and various techniques have been described for the surgical excision of JNA [7-13]. Endonasal endoscopic approach has now radically changed the way in which angiofibroma's are being managed [14] and an endoscopic classification scheme has also been described by Snyderman [15].

Endovascular embolization has emerged as an important tool in management of variety of hypervascular head and neck tumours, and recent developments in equipment and embolization materials has led to a more frequent usage [16].

While successful embolization is known to lead to better excision rates with lower intraoperative blood loss, the effect of variations in the vascular supply is not well documented in literature.

The authors aimed to evaluate the angiographic results with relation to intraoperative blood loss and audited the angiography and embolization images and the surgical outcomes in a series of consecutive cases of JNA operated endoscopically. We hypothesized that presence of additional feeders apart from internal maxillary and ascending pharyngeal arteries would increase the blood loss.

\section{Methods}

Clinical, angiographic and operative details of all consecutive patients of histopathologically y proven JNA cases operated during the period of August 2014 to March 2019 were reviewed retrospectively in this study. Chart review of clinical details and operative notes was done, and angiographic runs and images retrieved from PACS were analysed.

Preoperative diagnosis was done on contrast enhanced computerised tomography (CECT) scan, 13 patients also having undergone magnetic resonance imaging (MRI). All cases were discussed in clinico-radiological meeting to come to a consensus and treated accordingly. Tumours were classified according to Radkowski

${ }^{*}$ Correspondence to: Subhash Kumar, Department of Radiodiagnosis, All India Institute of Medical Science Patna, Phulwarisharif, Patna, Bihar, India, Tel: +918676836533; E-mail: drsubhash.dm@gmail.com

Key words: juvenile nasopharyngeal angiofibroma, embolization, endoscopic surgery

Received: November 07, 2019; Accepted: November 22, 2019; Published: November 27, 2019 
classification. Only Stage IIC and IIIA tumours were included in the study to remove the bias included due to relatively simple or overtly complex cases.

All patients had undergone 6-vessel cerebral digital subtraction angiography (DSA) examination in biplane DSA suite (Allura Clarity, Philips Medical Systems BV, Netherlands), under local anaesthesia, 24-48 hours prior to the surgery. In same session super selective polyvinyl alcohol (PVA) particle embolization using Progreat $2.7 \mathrm{Fr}$ microcatheter was done. 200-micron (180-300 micron) size particles (COOK Incorporated, Bloomington) were mostly used, in some cases 300 micron and occasionally 500 micron particles were also used. Gelfoam pledget was used in initial 3 cases to plug the internal maxillary artery (IMA) trunk after infusing particles and this practice was later abandoned. ICA feeders were not embolised. Additional arterial blood supply from superficial temporal artery (STA), middle meningeal artery (MMA), facial arteries were embolised where feasible using same microcatheter and particles. Single operator (SK) did the DSA and embolization.

Surgery was done 24-48 hours after embolization using endoscopy in all cases. Blood loss record was kept by the anaesthetist and retrieved by the operative note. In latter 10 cases coblation was also used. Follow up CECT was done within 72 hours to look for residual tumour. All surgeries had been done by single operator $(\mathrm{KB})$.
Statistical analysis was done on SPSS 21 software. Correlation was determined between single versus bilateral blood supply to blood loss and effect of ICA supply on blood loss (Figure 1).

\section{Results}

Total of 22 cases (mean 14.7 years \pm 2.7 years) of Radkwoski grade IIC (10) or IIIA (12) JNA were identified. Mean tumour size (average of three plane measurement) was $6.7 \mathrm{~cm}(5.8-12.5 \mathrm{~cm}$ range) measured on CECT exam. Clinical features are summarised in table 1.

Angiographic characteristics and embolization results are summarised in table 2. Embolization of ECA branches only were done (IMA, AscPhA, STA, MMA).

$15 / 22$ cases had bilateral external carotid artery (ECA) territory blood supply and 7/22 had additional supply from internal carotid artery (ICA) branches. Mean tumour devascularisation success was $60 \%$ angiographically (50\%-100\% range).

Pearson correlation between tumour devascularisation and blood loss was highly significant, the value of $\mathrm{R}$ being -0.8649 and $\mathrm{P}$ value being 0.002608 .

One-way ANOVA was used to check the difference between exclusive ECA group and ECA+ICA group. The f-ratio value is 5.55485 . The $\mathrm{p}$-value is .046183 . The result is significant at $p<0.05$. Statistically,
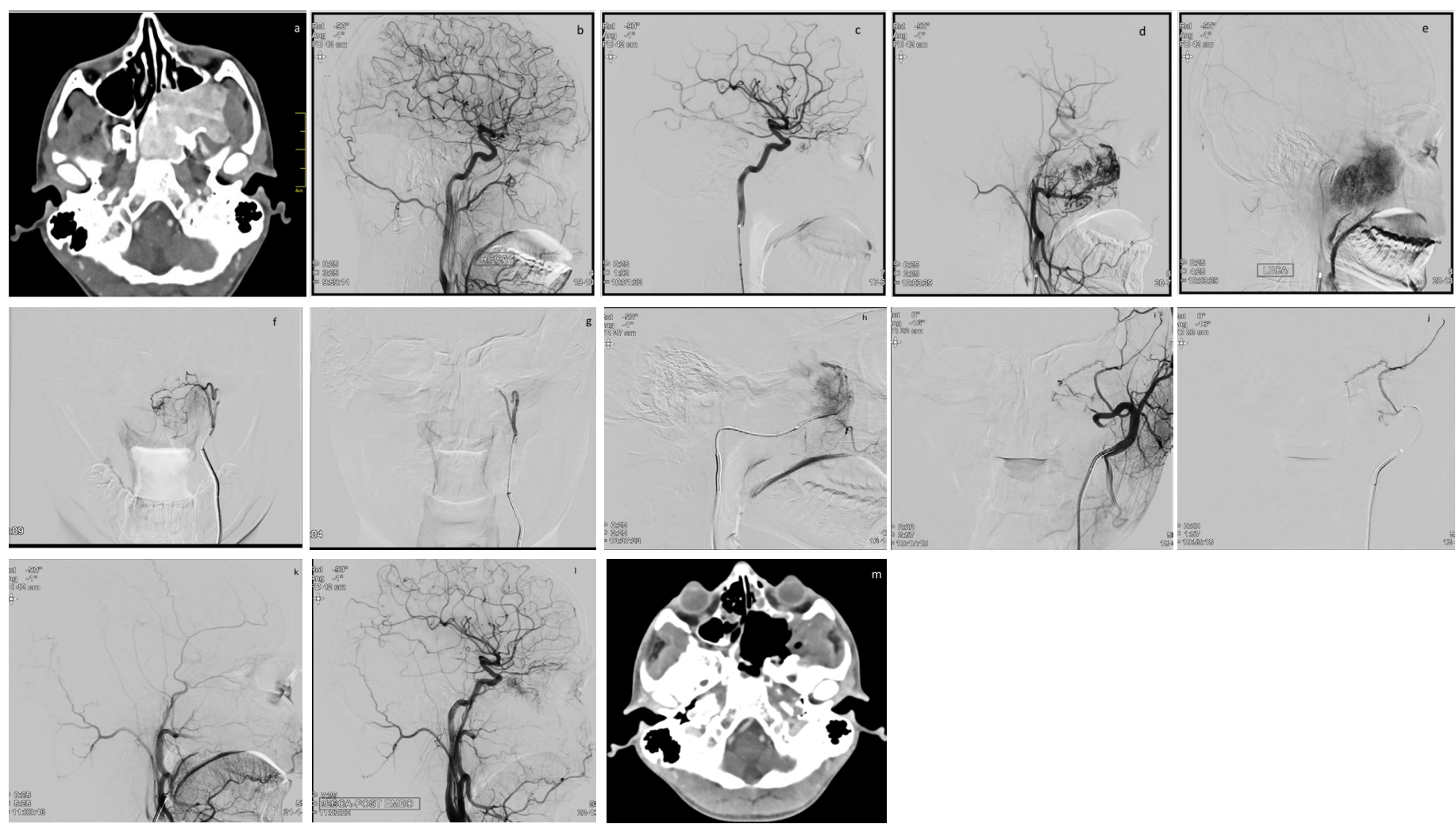

Figure 1. CT scan, DSA and embolization of a JNA case a) axial contrast enhanced CT scan showing an intensely enhancing mass in nasopharynx and extending into the pterygopalatine fossa b) Lat view, RCCA injection, showing normal anatomy without any tumor blush c) Lat view, LICA injection, showing tumor supply from ophthalmic artery branch d) mid phase and e) late phase of LECA injection, Lat view, showing hyper vascular tumor with multiple feeders from ECA branches f) super selective catheterization of left AscPA, and g) post PVA particle embolization image, AP views, showing complete devascularization of this territory h) super selective catheterization of left IMA, Lat view and i) post PVA particle embolization image, LECA run, AP view, showing complete devascularization of IMA territory, with additional collateral supply from left MMA j) Super selective left MMA catheterization, Lat view, and k) post PVA particle embolization, LECA injection, Lat view, showing complete ECA territory tumor devascularization 1) Final LCCA control angiogram, Lat view, showing residual tumor supply, which corresponds to the left ophthalmic artery supply m) Post-operative axial contrast enhanced CT scan showing complete excision of the tumor and post-operative cavity. CT: Computed Tomography; DSA: Digital Substraction Angiography; Lat: Lateral; RCCA: Right Common Carotid Artery; LICA: Left Internal Carotid Artery; LECA: Left External Cartid Artery; AscPA: Ascending Pharyngeal Artery; PVA: Polyvinyl Alcohol; IMA: Internal Maxillary Artery; AP: Anteroposterior; MMA: Middle Meningeal Artery. 
Table 1. Clinical features of study group patients

\begin{tabular}{|l|l|l|}
\hline SI & Feature & Cases $(\mathbf{n}=\mathbf{2 2})$ \\
\hline 1 & Epistaxis & $22 / 22(100 \%)$ \\
\hline 2 & Nasal obstruction & $15 / 22(68.18 \%)$ \\
\hline 3 & Rhinorrhea & $13 / 22(59.09 \%)$ \\
\hline 3 & Change in voice & $13 / 22(59.09 \%)$ \\
\hline 4 & Bulging mass in nostril & $8 / 22(36.36 \%)$ \\
\hline 5 & Headache & $8 / 22(36.36 \%)$ \\
\hline 6 & Proptosis & $3 / 22(13.63 \%)$ \\
\hline 7 & Difficulty in mastication & $1 / 22(4.54 \%)$ \\
\hline
\end{tabular}

Table 2. Angiographic and embolization results in study group patients

\begin{tabular}{|l|l|c|c|c|}
\hline SI & Arterial Supply & Nos. & $\begin{array}{c}\text { Mean Tumor } \\
\text { devascularization }\end{array}$ & $\begin{array}{c}\text { Mean Blood } \\
\text { loss (mL)* }\end{array}$ \\
\hline 1 & Exclusive ECA supply & $15 / 22$ & & 150 \\
\hline a & Unilateral IMA & $3 / 22$ & $90 \%$ & 120 \\
\hline b & Unilateral IMA + unilateral AscPhA & $4 / 22$ & $90 \%$ & 170 \\
\hline c & Bilateral IMA & $4 / 22$ & $90 \%$ & $150^{* *}$ \\
\hline d & Bilateral IMA + AscPhA & $4 / 22$ & $80 \%$ & 210 \\
\hline 2 & ECA and additional ICA supply & $7 / 22$ & 700 \\
\hline a & Unilateral IMA + unilateral ICA & $1 / 22$ & $70 \%$ & 410 \\
\hline b & $\begin{array}{l}\text { Unilateral IMA + unilateral AscPhA } \\
\text { unilateral ICA }\end{array}$ & $1 / 22$ & $70 \%$ & 380 \\
\hline c & Bilateral IMA supply + unilateral ICA & $1 / 22$ & $70 \%$ & 390 \\
\hline d & $\begin{array}{l}\text { Bilateral IMA supply + bilateral AscPhA } \\
+ \text { unilateral ICA }\end{array}$ & $2 / 22$ & $70 \%$ & 510 \\
\hline e & $\begin{array}{l}\text { Bilateral Internal Maxillary artery supply } \\
+ \text { bilateral AscPhA + bilateral ICA }\end{array}$ & $2 / 22$ & $55 \%$ & 1350 \\
\hline f & $\begin{array}{l}* * * \text { Ophthalmic artery territory artery/ } \\
\text { scleral blush visualisation during ECA } \\
\text { run }\end{array}$ & $3 / 22$ & $60 \%$ & 490 \\
\hline 3 & $* * * *$ Additional MMA supply & $4 / 22$ & $70 \%$ & 570 \\
\hline 4 & $* * * *$ Additional STA branch supply & $3 / 22$ & $80 \%$ & 480 \\
\hline 5 & $\begin{array}{l}* * * * * \text { Additional facial artery branch } \\
\text { supply }\end{array}$ & $4 / 22$ & $90 \%$ & 320 \\
\hline & & & \\
\hline
\end{tabular}

there was no significant difference between unilateral versus bilateral blood supply.

No neurological complications were seen. One patient developed iliac artery thrombus formation which was treated successfully treated with intraarterial thrombus aspiration and urokinase infusion.

Complete endoscopic tumour removal was obtained in 19 cases with average operative time of 155 minutes (50 minutes-330 minutes range). The recent 10 cases had been done using coblation device. Postoperative CECT was done within 72 hours. 3 cases had residual lesion (mean size $2.1 \mathrm{~cm}$ ) out of which 2 cases underwent repeat surgery with complete excision and one residual lesion was kept on follow up. The mean blood loss during surgery was $362 \mathrm{ml} \pm 176.2 \mathrm{ml}$ (range $50 \mathrm{ml}$ $1500 \mathrm{ml}$ ). None but two patient received autologous blood transfusion during surgery. No perioperative surgical complications occurred.

\section{Discussion}

Since past few decades, endoscopic resection and embolization, both are becoming increasingly popular in JNA management. Preoperative embolization reduces blood loss while decreasing the risk of massive haemorrhage, curtails operative duration, allows better intraoperative field visibility, decreases risk to adjacent tissue and possibly better respectability as well as reduction in tumour recurrence [17].

Preoperative embolization is effective in reducing intraoperative blood loss. Even relatively older studies using gelfoam embolization have had this finding. In a study by Li et al. [18] Gelfoam embolization decreased blood loss from $1136 \mathrm{~mL}$ to $677 \mathrm{~mL}$ and transfusion from average $836 \mathrm{~mL}$ to $400 \mathrm{~mL}$.

Endoscopic surgery has evolved as an exciting option [14,15,19]. It has now become the primary operative technique except for the most advanced tumours. Studies and reviews have demonstrated comparable tumour control with reduced morbidity in endonasal endoscopic approach compared to open approach [20-22].

In their systematic analysis of 57 studies over 21 years, Boghani et al. [22] showed that the average blood loss in patients undergone embolization prior to endoscopic resection averaged $406.7 \mathrm{~mL}$ versus $828.3 \mathrm{~mL}$ in nonembolized patient. In open surgical cases, blood loss was $685.0 \mathrm{~mL}$ in embolised patients versus $1912.1 \mathrm{~mL}$ in non-embolised patients. In the same analysis, the authors have reported average blood loss of $544.0 \mathrm{~mL}, 490.0 \mathrm{~mL}$, and $1579.5 \mathrm{~mL}$ for endoscopic, endoscopicassisted, and open surgical cases, respectively.

JNA primarily derives its blood supply from the distal branches of the IMA, classically the sphenopalatine artery, but with contributions from others ECA branches also like AscPhA, descending palatine and posterior superior alveolar arteries and their branches [23]. Subsequent to tumour growth, recruitment of blood supply from the ICA and contralateral vessels take place [24].

Overdevest et al. [25] have described the vascular supply pattern of JNA. Their systematic review of 828 cases found ICA supply in $35.6 \%$ of tumours, and $30.8 \%$ of tumours received bilateral vascular supply. Their own institutional data $(\mathrm{n}=26)$ indicated $69 \%$ had bilateral supply. Meta-analysis of data from 5 studies demonstrated ICA/ bilateral arterial supply to be predictive of increased operative blood loss $(P<0.01)$. Wu et al. [26] have reported $36 \%$ cases to have bilateral blood supply.

Our own study also corroborates this finding, 59.1\% patients having bilateral blood supply, and we observed a rather disproportionate effect of ICA supply on amount of blood loss. The operative team reported the well embolised ECA supplied tumours to have 'negligible' bleed while the ones with ICA supply were described with a 'head shake' rather than a smile. We attempted to analyse this and hypothesize that use of 200-micron sized particles might have resulted in incomplete occlusion of the intra tumoral channels and over next 24-48 hours these might have been increasingly perfused via the ICA supply by opening of the collaterals and the intra tumoral connections. In order to obviate this, now we are resorting to usage of 100 -micron particles where feasible, however with smaller size particles there is always a chance of increased complications, and our staple is still 200 micron particle.

Ballah et al. [27] have reported average blood loss of $336 \mathrm{~mL}$ in patients with strict ECA supply and $842 \mathrm{~mL}$ in patients with both ECA and ICA supply, having embolised only the ECA territory with PVA particles. The findings are in resonance with our own findings.

Interestingly the authors also reported statistically significant difference in surgical blood loss using Andrews ( $p=0.008$ ), Radkowski $(\mathrm{p}=0.015)$, and University of Pittsburgh Medical Centre (UPMC; $\mathrm{p}=0.015)$ preoperative tumour staging systems.

Goal of embolization is to reduce vascularity by at least $80 \%$ [17], and this is achievable in tumours with ECA supply using the standard embolization technique used. However, as seen from table 2, tumours with additional supply from ICA, ophthalmic or MMA have embolization of 55\%-70\%, which might lead to increased blood loss.

We used coblation during the latter part of this series in 10/22 cases. Coblation allows for decreased bleeding, less need for instrumentation, 
and improved visualization and may translate into improved resection and decreased surgical timings [28]. Our centre now routinely uses it in all cases of JNA. There was however similar blood loss in patients operated with or without coblation (380 vs. $410 \mathrm{ml}$ respectively), however with significantly decreased surgical timings (130 min. vs 190 $\min$.).

Multiple classification systems exist JNA. The University of Pittsburg Medical Center (UPMC) staging incorporates the residual ICA supply after ECA territory embolisation [15] and our findings also are in line with the same.

The authors utilise the Radkowski staging system in routine clinical use as well as for research purposes.

We utilised the Radkowski classification in this study to include the large tumour without significant intracranial extension, so as to ascertain the role of the ICA supply in blood loss. In the article by Synderman blood loss of more than $1000 \mathrm{ml}$ was seen in tumours having residual ICA supply (UPMC stage IV and V) while stages I and III did not have residual ICA supply and had minimal blood loss even if tumours were large and extended into the paranasal sinuses and pterygopalatine fossa.

ICA supplied lesions have been embolised using direct percutaneous embolization with liquid embolics (nBCA glue or Onyx) [29-31]. Elhammady et al. [30] had lower bleeding $(412 \mathrm{~mL})$ with Onyx as against PVA embolization ( $862 \mathrm{~mL})$. Kasem et al. [31] had bleeding of $150 \mathrm{~mL}$ only with use of cyanoacrylate glue and PVA. However, liquid embolic's are known to have neurological complications including stroke and vision loss due to inadvertent intracranial embolization through collaterals $[19,32]$, hence we do not opt for it in general, and trust our surgeons to do their best.

Endovascular parent vessel sacrifice of the ICA is also an option if an angiographic balloon occlusion test shows adequate collateral blood supply.

Embolization in MMA or AscPhA territory can lead to cranial nerve palsy [33], however we did not have such event even though 13/22 and 4/22 patients had AscPhA and MMA territory embolization.

Intracranial extension of JNA leads to increased surgical complications including ophthalmoplegia, facial paresis, intranasal crusting, more bleeding [34]. This particular series of cases was also not designed to treat cases with intracranial extension which are more prone for ICA supply.

There have also been reports against routine use of preoperative embolization [35-37]. It has been propounded to even increase tumour recurrence rate [35]. Also, for smaller lesions, endoscopic surgery without embolization has been considered a feasible option. In a study by Fonseca et al. [36] the authors found similar blood loss in non-embolised Fisch Grade I-III tumours as compared with embolised tumours in the literature. Benefit of embolization in low-grade tumours is less clear cut and removal is easier in such tumours [37]. Such reports may have some merit also, since smaller tumours are likely to have only ECA supply and with good intraoperative control, significant bleeding can be mitigated. On the other hand, as shown in out article, if there is any additional supply, then chance of bleed would be much higher.

\section{Conclusion}

Angiographic analysis of Radkowski grade IIc and IIIa tumours reveal significant number to have ICA supply, bilateral supply and additional ECA branch supply (MMA and STA), apart from IMA and AScPhA. Bilateral supply did not have any effect on bleeding, however additional arterial supply had significant effect on extent of bleed. Efforts have to be made to devise better techniques to mitigate this challenge.

\section{Acknowledgements}

The authors thank the Department of Anesthesiology, AIIMS Patna, for meticulous record keeping, Dr Alok Ranjan, Department of Community and Family Medicine, AIIMS Patna, for statistical analysis, and Mr Sanjeev Kumar, Radiographic Technician Grade 1, AIIMS Patna, for working with the images.

\section{References}

1. Biswas G, Ghosh SK, Mukhopadhya S, Bora H (2002) A clinical study of nasopharyngeal masses. Indian J Otolaryngol Head Neck Surg 54: 193-195. [Crossref]

2. Schiff M (1959) Juvenile Nasopharyngeal Angiofibroma: A theory of pathogenesis Laryngoscope 69: 981-1016. [Crossref]

3. Sellars SL (1980) Juvenile Nasopharyngeal Angiofibroma. S Afr Med J 58: 961-964 [Crossref]

4. Martin H, Ehrlich HE, Abels JC (1984) Juvenile Nasopharyngeal Angiofibroma. Ann Surg 127: 513-536. [Crossref]

5. Nicolai P, Schreiber A, Bolzoni Villaret A (2012) Juvenile angiofibroma: evolution of management. Int J Pediatr: 412545. [Crossref]

6. Sessions RB, Bryan RN, Naclerio RM, Alford BR (1981) Radiographic staging of juvenile angiofibroma. Head Neck Surg 3: 279-283. [Crossref]

7. Fisch U (1983) The infratemporal fossa approach for nasopharyngeal tumors Laryngoscope 93: 36-44. [Crossref]

8. Chandler JR, Goulding R, Moskowitz L, Quencer RM (1984) Nasopharyngeal angiofibromas: staging and management. Ann Otol Rhinol Laryngol 93: 322-329. [Crossref]

9. Andrews JC, Fisch U, Valavanis A, Aeppli U, Makek MS (1989) The surgical management of extensive nasopharyngeal angiofibromas with the infratemporal fossa approach. Laryngoscope 99: 429-437. [Crossref]

10. Radkowski D, McGill T, Healy GB, Ohlms L, Jones DT (1996) Angiofibroma. Changes in staging and treatment. Arch Otolaryngol Head Neck Surg 122: 122-129. [Crossref]

11. Onerci M, Ogretmenoglu O, Yucel T (2006) Juvenile nasopharyngeal angiofibroma: a revised staging system. Rhinology 44: 39-45. [Crossref]

12. Mendenhall WM, Werning JW, Hinerman RW, Amdur RJ, Villaret DB (2003) Juvenile Nasopharyngeal Angiofibroma. J HK Coll Radiol 6: 15-19.

13. Ardehali MM, Ghorbani J (2011) Juvenile Nasophryngeal Angiofibroma, New Aspects in Management. Iranian J Otorhinolary 23: 61-68.

14. Nicolai P, Berlucchi M, Tomenzoli D, Capiello J, Trimarchi M, et al. (2003) Endoscopic surgery of Juvenile angiofibroma: When and how. Laryngoscope 113: 775782. [Crossref]

15. Snyderman CH, Pant H, Carrau RL, Gardner P (2010) A new endoscopic staging system for angiofibromas. Arch Otolaryngol Head Neck Surg 136: 588-594. [Crossref]

16. Ashour R, Aziz-Sultan A (2014) Preoperative Tumor Embolization. Neurosurg Clin N Am 25: 607-617. [Crossref]

17. Duffis EJ, Gandhi CD, Prestigiacomo CJ, Abruzzo T, Albuquerque F, et al. (2012) Head, neck, and brain tumor embolization guidelines. J Neurointerv Surg 4: 251-255. [Crossref]

18. Li JR, Qian J, Shan XZ, Wang L (1998) Evaluation of the effectiveness of preoperative embolization in surgery for nasopharyngeal angiofibroma. Eur Arch Otorhinolaryngol 255: 430-432. [Crossref]

19. Janakiram N, Sharma SB, Panicker VB, Srinivas CV (2016) A Drastic Aftermath of Embolisation in Juvenile Nasopharyngeal Angiofibroma. Indian J Otolaryngol Head Neck Surg 68: 540-543. [Crossref]

20. Wilson MN, Nuss DW, Zacharia BE, Snyderman CH (2019) Surgical management of juvenile nasopharyngeal angiofibroma. Operative Tech Otolar 30: 22-29. 
21. Pryor SG, Moore EJ, Kasperbauer JL (2005) Endoscopic versus traditional approaches for excision of juvenile nasopharyngeal angiofibroma. Laryngoscope 115: 1201-1207. [Crossref]

22. Boghani Z, Husain Q, Kanumuri VV, Khan MN, Sangvhi S, et al. (2013) Juvenile nasopharyngeal angiofibroma: a systematic review and comparison of endoscopic, endoscopicassisted, and open resection in 1047 cases. Laryngoscope 123: 859-869. [Crossref]

23. Prasanna S, Ravikumar A, Somu L, Reddy S (2014) Juvenile Nasopharyngeal Angiofibroma: Our Experience. J Evolution Medical Dental Sci 3: 559-564.

24. Mattei TA, Nogueira GF, Ramina R (2011) Juvenile nasopharyngeal angiofibroma with intracranial extension. Otolaryngol Head Neck Surg 145: 498-504. [Crossref]

25. Overdevest JB, Amans MR, Zaki P, Pletcher SD, El-Sayed IH (2018) Patterns of vascularization and surgical morbidity in juvenile nasopharyngeal angiofibroma: A case series, systematic review, and meta-analysis. Head \& Neck 40: 428-443. [Crossref]

26. Wu AW, Mowry SE, Vinuela F, Abemayor E, Wang MB (2011) Bilateral vascular supply in juvenile nasopharyngeal angiofibromas. Laryngoscope 121: 639-643. [Crossref]

27. Ballah D, Rabinowitz D, Vossough A, Rickert S, Dunham B, et al. (2013) Preoperative angiography and external carotid artery embolization of juvenile nasopharyngeal angiofibromas in a tertiary referral paediatric centre. Clin Radiol 68: 1097-1106. [Crossref]

28. Cannon DE, Poetker DM, Loehrl TA, Chun RH (2013) Use of coblation in resection of juvenile nasopharyngeal angiofibroma. Ann Otol Rhinol Laryngol 122: 353-357. [Crossref]

29. Gemmete JJ, Patel S, Pandey AS, Sullivan SE, McKean EL, et al. (2012) Preliminary Experience with the Percutaneous Embolization of Juvenile Angiofibromas Using Only Ethylene-Vinyl Alcohol Copolymer (Onyx) for Preoperative Devascularization Prior to Surgical Resection. AJNR Am J Neuroradiol 33: 1669-1675. [Crossref]
30. Elhammady MS, Johnson JN, Peterson EC, Aziz-Sultan MA (2011) Preoperative embolization of juvenile nasopharyngeal angiofibromas: transarterial versus direct tumoral puncture. World Neurosurg 76: 328-334; discussion 263-265. [Crossref]

31. Kasem MAHO, Awad AS, Al Bosraty HADM, Kamel AI (2016) Preoperative embolization of nasopharyngeal angiofibromas: The role of direct percutaneous injection of cyanoacrylate glue in conjunction with particulate endovascular approach. Egyptian J Radiol Nucl Med 47: 1431-1441.

32. Ramezani A, Haghighatkhah H, Moghadasi H, Taheri MS, Parsafar H (2010) A case of central retinal artery occlusion following embolization procedure for juvenile nasopharyngeal angiofibroma. Indian J Ophthalmol 58: 419-421. [Crossref]

33. Lajaunias P (1980) Nasopharyngeal angiofibromas: hazards of embolization. Radiology 136: 119-123. [Crossref]

34. Leong SC (2013) A systematic review of surgical outcomes for advanced juvenile nasopharyngeal angiofibroma with intracranial involvement. Laryngoscope 123: 11251131. [Crossref]

35. Lloyd G, Howard D, Phelps P, Cheesman A (1999) Juvenile angiofibroma: the lessons of 20 years of modern imaging. J Laryngol Otol 113: 127-134. [Crossref]

36. Fonseca AS, Vinhaes E, Boaventura V, de Andrade NA, Dias LA, et al. (2008) Surgical Treatment of Non-embolized Patients with Nasoangiofibroma. Braz J Otorhinolaryngol 74: 583-587. [Crossref]

37. Moulin G, Chagnaud C, Gras R, Gueguen E, Dessi P, et al. (1995) Juvenile nasopharyngeal angiofibroma: comparison of blood loss during removal in embolized group versus nonembolized group. Cardiovasc Intervent Radiol 18: 158-161. [Crossref]

Copyright: @2019 Kumar S. This is an open-access article distributed under the terms of the Creative Commons Attribution License, which permits unrestricted use, distribution, and reproduction in any medium, provided the original author and source are credited. 